


About IJMA
International Journal of Medical Arts is the Official Scientific Journal
of the Damietta Faculty of Medicine, Al-Azhar University, Egypt
It is an International, Open Access, Double-blind, Peer-reviewed,
monthly-published (starting January 2022) Journal
The First Issue was published in July 2019
Published under the following license: Creative Commons
Attribution-ShareAlike 4.0 International Public License (CC BY-SA
4.0).
The Egyptian Knowledge Bank hosts the web site and supports
IJMA follows the regulations of the International Committee of
Medical Journal Editors
IJMA is a member of the International Society of Managing and
Technical Editors
IJMA is indexed in the "Directory of Open Access Journals"
[Indexed on 15 January 2021], Index Copernicus and J-Gate [29-6-
IJM21].
IJMA Listed in
"Publons", "Academic resource index [ResearchBib]", "Electronics journal
Jibrary", "Eurasian Scientific Journal Index", World Catalogue of Scientific
WorldCat and "Citefactor"




\begin{tabular}{c}
$\begin{array}{c}\text { Available online at Journal Website } \\
\text { https://ijma.journals.ekb.eg/ } \\
\text { Main Subject [Ophthalmology] }\end{array}$ \\
\hline
\end{tabular}

Original Article

\title{
Actual Depth Ablation in LASIK and FEMTOLASIK Surgeries for Correction of Myopia and Myopic Astigmatism
}

\author{
Adel M. Abdul Wahab Khalil, Mona EI Sayed Ali * \\ ${ }^{1}$ Department of Ophthalmology, Faculty of Medicine [For Girls], Al-Azhar University, Cairo, Egypt
}

\begin{tabular}{|c|c|}
\hline \multicolumn{2}{|c|}{ Article information } \\
\hline Submitted: & $13-11-2021$ \\
\hline Accepted: & $17-01-2022$ \\
\hline \multicolumn{2}{|c|}{ DOI: 10.21608/ijma.2022.214546 } \\
\hline \multicolumn{2}{|c|}{$\begin{array}{l}\text { *Corresponding author } \\
\text { Email: } \underline{\text { dr_mona1408@ hotmail.com }}\end{array}$} \\
\hline $\begin{array}{l}\text { Citation: Kha } \\
\text { Depth Al } \\
\text { FEMTOLAs } \\
\text { Myopia and } \\
2022 \text { Jan; } \\
10.21608 / \text { ijn }\end{array}$ & $\begin{array}{l}\text { alil AMA, Ali ME. Actual } \\
\text { blation in LASIK and } \\
\text { SIK Surgeries for Correction of } \\
\text { Myopic Astigmatism. IJMA } \\
4 \text { [1]: 2088-2094 [DOI: } \\
\text { na.2022.214546]. }\end{array}$ \\
\hline
\end{tabular}

\section{ABSTRACT}

Background: Proper calculation of ablation depth associated with LASIK and FEMTOLASIK surgeries is mandatory to estimate the post-refractive surgery remaining stroma to avoid the possibility of post-operative ectasia and to correct the maximum error to meet the patient's needs and safety.

Purpose: The current work aimed to assess the actual depths of ablation after the LASIK versus the FEMTO-LASIK surgeries.

Patients and Methods: Forty eyes of 20 patients were included in this prospective nonrandomized interventional study. They had myopia or myopic astigmatism, and scheduled for LASIK or FEMTOLASIK surgery. Pentacam was used to check the thickness of the thinnest corneal location and to exclude the possibility of keratoconus. They were divided into two groups according to the technique used to correct the error. Group I for LASIK and Group II for FEMTOLASIK surgery. Ablation was performed in all cases using the Allegretto excimer laser machine. After surgery, all patients received a combination of topical tobramycin $0.3 \%$ and dexamethasone $0.1 \%$ eye drops four times daily for 10 days, and topical Sodium Hyaluronate eye drops [2 mg/ml] four times daily for one month. All patients were examined at one day and one week postoperatively for evidence of flap malposition, striae, epithelial defects, or diffuse lamellar keratitis. Pentacam was used for follow up at 3 months after surgery to re-evaluate the thinnest central location.

Results: In group I, the mean actual tissue ablation per one diopter was 13.3 microns for $6.5 \mathrm{~mm}$ treatment zone, and 11.9 microns for $6.0 \mathrm{~mm}$ treatment zone, while in group II, it was 13.4 microns for 6.5 treatment zone, and 11.8 microns for 6.0 treatment zone. There was insignificant difference between actual tissue ablation following the LASIK versus the FEMTOLASIK surgeries.

Conclusion: The actual ablation depth should be considered to calculate the remaining stromal depth after LASIK or FEMTOLASIK surgeries for treatment of myopia or myopic astigmatism to avoid the possibility of post- LASIK or FEMTOLASIK ectasia and to correct the maximum error that meets the patient's needs.

Keywords: LASIK; FEMTOLASIK; Myopia; Myopic Astigmatism; Excimer laser; Ablation; Pentacam.

This is an open-access article registered under the Creative Commons, ShareAlike 4.0 International license [CC BY-SA 4.0] [https://creativecommons.org/licenses/by-sa/4.0/legalcode.

\section{INTRODUCTION}

Laser in situ keratomileusis [LASIK] is a predictable, effective, stable, and safe surgical technique to correct myopia and myopic astigmatism $^{[1]}$.

Many studies have tried to establish the risk factors for the post-LASIK keratectasia which represent one of the most serious complications of the LASIK surgery. These risk factors include age $[<30$ years], residual stromal bed thickness $[<300 \mu \mathrm{m}]$, preoperative central corneal thickness [CCT] $\left[<\begin{array}{lll}<00 & \mu \mathrm{m}\end{array}\right]$, preoperative mean keratometry readings [> $47.00 \mathrm{D}]$, manifest preoperative refraction spherical equivalent [SE] [more than $-8.00 \mathrm{D}$ ], against-the-rule astigmatism, and percent of tissue altered [PTA] [> 40\%] ${ }^{[1-5]}$. 
The accurate estimation of ablation depth is a crucial factor regarding safety because it determines the residual stromal bed and the postoperative total corneal thickness ${ }^{[6]}$.

In practice, the only ablation depth estimation and the residual stromal bed thickness available to the surgeon is the one predicted by the laser machine software, when the treatment is programmed. Therefore, the surgeon works with this predicted value as a "reference ablation depth" in spite of the fact that it is a prediction and not an actual measurement ${ }^{[7]}$.

Objective measurements of corneal thickness rely on different techniques. Ultrasound pachymetry was the technique of choice for many years. It has drawbacks as it requires topical anesthesia and corneal contact, bearing potential risk of epithelial abrasion or infection and its results are operator dependent ${ }^{[8]}$.

Recently, several noncontact techniques are available to measure the central corneal thickness with more flexibility including, systems based on slit-scanning [Orbscan], Scheimpflug camera [Pentacam], optical coherence tomography, and optical lowcoherence reflectometry. They are now widely used in everyday practice ${ }^{[\mathbf{9 , 1 0}]}$.

The motivation that directed us to perform this study was on February, 2014, where we did Lasik surgery for a 26 years old male patient to correct his myopic astigmatism [Sph.: -8.00 D, Cylinder: -0.50 D, Axis: 120 degrees]. Least corneal thickness was 552 microns, treatment zone was $6.5 \mathrm{~mm}$, flap thickness was 110 microns, calculated tissue ablation was 123 microns, calculated residual stroma was 319 microns, and the calculated least corneal thickness after surgery was 429 microns. On December, 2014, the patient attends the clinic with residual myopia [Sph.: 1.50 D, Cylinder: -0.00 D]. Pentacam examination revealed that the least corneal thickness was 443 microns [14 microns more than the previously laser machine calculated thickness].

On November, 2017, we performed another Lasik surgery for a 22 years old female patient, with myopic astigmatism [Sph.: -4.50 D. Cylinder: -1.25 D, Axis: 180 degrees]. Her least corneal thickness was 532 microns, treatment zone was $6.5 \mathrm{~mm}$, flap thickness was 110 microns, calculated tissue ablation was 87 microns, calculated residual stroma was 335 microns, and the calculated least corneal thickness after surgery was 445 microns]. On April, 2014, the patient attends with residual myopic astigmatism [Sph.: $-1.24 \mathrm{D}$, Cylinder: 0.75 D, Axis: 10 degrees]. Pentacam examination revealed that the least corneal thickness was 455 microns [10 microns more than the previously calculated thickness]

These two cases directed our attention to reevaluate the programmed laser platform's software to give the patient his chance for full correction and to avoid the tendency of surgeons to plan the under-correction to keep enough residual stromal thickness in some cases.

\section{THE AIM OF THE WORK}

The aim of this study was to measure the actual depth of ablation following LASIK and FEMTOLASIK surgeries, and to compare between the depths of ablation following the LASIK versus the FEMTO-LASIK surgeries.

\section{PATIENTS AND METHODS}

This study was a prospective, interventional and non-randomized. It was held at I-Vision Hospital in the period between November, 2020 and July, 2021. Forty eyes in 20 patients were included in this study. They were 9 males [45\%], and 11 females [55\%]. Their mean age was 28.15 \pm 3.96 years [Range 21-38 years]. They were diagnosed as myopic or myopic astigmatism and were referred to the hospital for correction of their errors of refraction. They were prepared for LASIK or FEMTOLASIK surgeries.

\section{Inclusion criteria}

Myopia [less than -10.00D], astigmatism [less than $-4.00 \mathrm{D}]$ and myopic astigmatism [steep meridian less than $-12.00 \mathrm{D}$ ], age more than 21 years, clear cornea, normal fundus examination, normal intraocular pressure, no 
history of previous eye surgery, no other ocular pathology, cooperative patient, and normal Pentacam examination with central corneal thickness and keratometric readings safe enough to get post LASIK or post Femto Lasik residual stromal thickness more than 300 microns, and post-refractive surgery keratometric readings more than $35.0 \mathrm{D}$ in the flat meridian.

\section{Exclusion criteria}

myopia [more than $-10.00 \mathrm{D}$ ], astigmatism [more than $-4.00 \mathrm{D}$ ] and myopic astigmatism [steep meridian more than $-12.00 \mathrm{D}$ ], age less than 21 years, any corneal scarring, abnormal fundus examination, glaucoma, history of previous eye surgery, other ocular pathology, if the calculated thinnest corneal thickness is less than 300 microns or the flat meridian is less than $35 \mathrm{D}$, autoimmune or collagen diseases and uncooperative patient.

Patients were subjected to full history taking, uncorrected visual acuity [UCVA], cycloplegic refraction, best corrected visual acuity [BCVA] [UCVA \& BCVA were converted to the decimal visual acuity], slit lamp examination for the anterior segment, fundus examination using the indirect ophthalmoscopy, applanation tonometry, and Pentacam examination to exclude the possibility of keratoconus, to check the thinnest corneal thickness, and to document the Keratometric readings. For patients with a history of wearing contact lenses, patients had a minimum rest period of at least 8 days before preparation for the procedure.

\section{Ethical consideration}

The nature of the procedure was explained to each patient prior to surgery including its benefits, and the possible complications. An informed written consent was signed by each patient.

Patients were divided into two groups according to the technique used to correct the error:

Group I: LASIK surgery was used to correct the error. It included 26 eyes in 13 patients, 6 males [46.2\%] and 7 females [53.8\%].

Group II: Femto LASIK was the surgery used. It included 14 eyes in 7 patients, 3 males [42.9\%] and 4 females [57.1\%].

Surgery was performed after sterilization of the periocular area using povidone-iodine, a plastic drape was then applied. Topical anesthesia using $0.4 \%$ benoxinate hydrochloride was applied to the conjunctival sac 3 times before surgery with an interval of 2 minutes in-between. A wire speculum was then applied to expose the globe.

In group I, the microkeratome was used in all cases to form a lamellar hinged superior flap [110 microns] using the Moria II microkeratome [Figure 1]. In group II: corneal flap [110 microns] was formed using the Femto-Laser machine [Wave Light FS200] [Figure 2].

After formation of the flap in both groups, laser was focused on the cornea [using the Excimer-Laser Wave Light EX500] [figure 3] and centered on the pupil with the activated eye tracker. The flap was lifted and the ablation was aimed at the dry stromal bed in a $6.5 \mathrm{~mm}$ or $6.0 \mathrm{~mm}$ treatment zone, depending on the scotopic pupil size. The flap was then repositioned, and the interface was irrigated using the balanced saline solution, and the cornea was then dried using a flow of air. Slit lamp examination was performed immediately postoperatively to confirm proper flap reposition and to exclude flap wrinkles.

After surgery, all patients received combination of topical $0.3 \%$ tobramycin / $0.1 \%$ dexamethasone eye drops four times daily for 10 days, together with topical $[2 \mathrm{mg} / \mathrm{ml}]$ sodium hyaluronate eye drops four times daily for one month. Post LASIK or post FemtoLASIK follow up was done at 1 day and 1 week postoperatively for evidence of flap malposition, flap striae, epithelial defects and diffuse lamellar keratitis. Follow up using the same Pentacam machine was done 3 months after surgery to re-evaluate the least corneal thickness. 


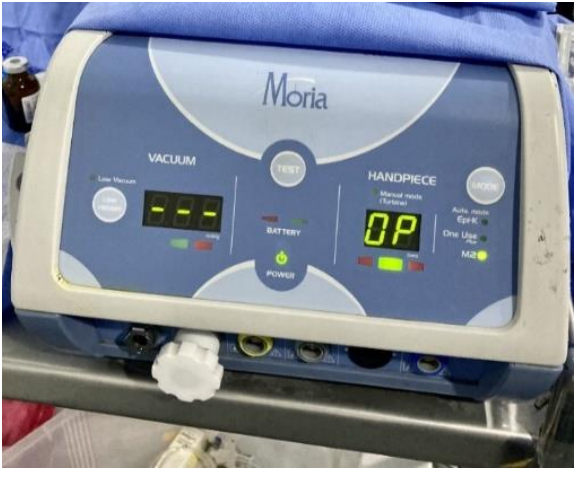

Figure [1]: Moria II Microkeratome

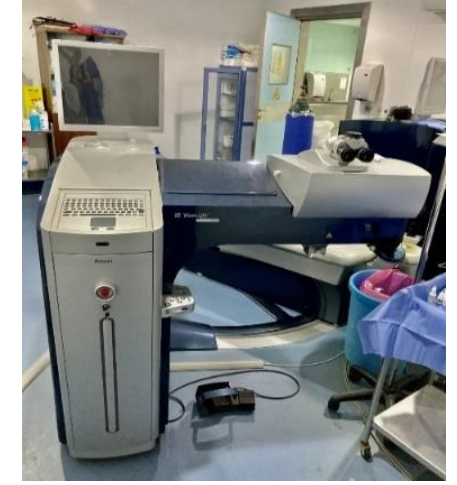

Figure [2]: Femto-Laser machine [Wave Light FS200].

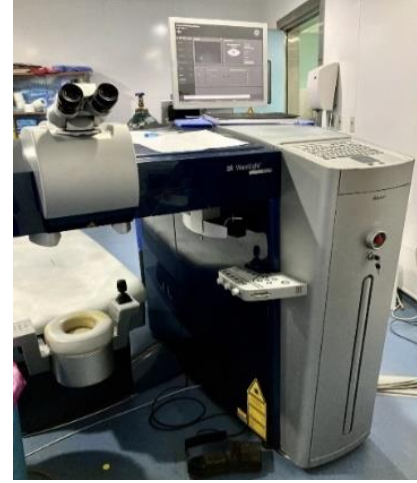

Figure [3]: Excimer-Laser Wave Light EX500
Data Collection and Analysis: Data were collected, reviewed, coded and fed to an excel sheet and then transferred to the statistical package of social sciences software package. Quantitative data were presented as mean, standard deviations and ranges when parametric and median with inter-quartile range [IQR] when non-parametric and percentiles was used to assess the distribution of some parameters. Also, qualitative variables were presented as number and percentages. Comparison between groups regarding qualitative data was done by using Chi-square test and/or Fisher exact test when the expected count in any cell found less than 5. Comparison between two independent groups with quantitative data and parametric distribution was done by using independent t-test. Confidence interval was set at $95 \%$ and the margin of error accepted was set at $5 \%$. So, the $\mathrm{p}$-value was considered significant if $\mathrm{p}<0.05$.

\section{RESULTS}

Males represented $46.2 \%$ and females 53.8 of group I, compared to $42.9 \%$ males and $57.1 \%$ females in group II. The mean age of group I was $28.3 \pm 4.05$ years [Range $24-38$ years], while in Group II the mean age was $27.7 \pm 4.07$ years [Range $21-33$ years]. The differences between both groups as regards the age and sex were statistically insignificant $[\mathrm{P}$ values were 0.74 and 0.81 respectively].

Table I, illustrates the mean \pm SD of the spherical and cylindrical errors, thinnest corneal location, flap thickness, calculated tissue ablation per eye and per one diopter for the 6.5 and $6.0 \mathrm{~mm}$ treatment zones. The difference between both groups as regards calculated tissue ablation per eye and the calculated tissue ablation per one diopter in 6.5 and 6.0 ablation zones were statistically insignificant [P values were $0.31,0.24$ and 0.36 respectively].

In Group I at three months postoperatively, Pentacam examination revealed that; Mean + SD of actual thinnest corneal location was: $465.88+49.8$ microns. Mean + SD of actual tissue ablation per eye was: $83.91+55.5$ microns. Mean + SD of actual tissue ablation per one diopter was: $13.3+0.73$ microns for $6.5 \mathrm{~mm}$ treatment zone, and $11.9+0.68$ microns for $6.0 \mathrm{~mm}$ treatment zone. While in Group II at three months postoperatively; the mean + SD of actual thinnest corneal location was: $475.13+54.12$ microns. Mean + SD of actual tissue ablation per eye was: $83.85+$ 30.41 microns. Mean + SD of actual tissue ablation per one diopter was: $13.4+0.73$ microns for 6.5 treatment zone, and $11.8+0.59$ microns for 6.0 treatment zone.

Table 2, illustrates the mean $+\mathrm{SD}$ of the actual tissue ablation per eye, mean actual tissue ablation per one diopter for the 6.5 and $6.0 \mathrm{~mm}$ treatment zones in Groups I and II, 3 months postoperatively. There were insignificant statistical differences between the LASIK and the Femto-LASIK groups as regards the actual tissue ablation in both the 6.5 $\mathrm{mm}$ and $6.0 \mathrm{~mm}$ treatment zones $[\mathrm{P}=0.84$, 0.71 and 0.46 respectively]. 
Table [1]: Spherical and cylindrical errors, thinnest corneal location, flap thickness, calculated tissue ablation per eye and per one diopter for the 6.5 and $6.0 \mathrm{~mm}$ treatment zones

\begin{tabular}{|l|c|c|c|}
\hline & Group I & Group II & P value \\
\hline Mean Spherical Error + SD [D] & $-4.29+2.02$ & $-4.50+1.91$ D & 0.22 \\
\hline Mean Cylindrical Error + SD & $-0.96+0.85$ & $-1.05+0.94$ D & 0.47 \\
\hline Mean Thinnest Corneal Location + SD [microns] & $549.19+70.37$ & $558.85+24.6$ & 0.31 \\
\hline Flap Thickness [microns] & 110 & 110 & 0,62 \\
\hline $\begin{array}{l}\text { Mean Calculated Tissue Ablation per Eye + SD } \\
\text { [microns] }\end{array}$ & $90.12+55.5$ & $91.57+13.1$ & 0.31 \\
\hline $\begin{array}{l}\text { Mean Calculated Tissue Ablation Per One Diopter } \\
\text { for the 6.5 Treatment Zone + SD [microns] }\end{array}$ & $14.4+0.66$ & $14.3+0.69$ & 0.24 \\
\hline $\begin{array}{l}\text { Mean Calculated Tissue Ablation Per One Diopter } \\
\text { for the 6.0 Treatment Zone + SD [microns] }\end{array}$ & $13.1+0.58$ & $13.2+0.62$ & 0.36 \\
\hline
\end{tabular}

Table [2]: Actual tissue ablation in Groups I and II, 3 months postoperatively

\begin{tabular}{|c|c|c|c|}
\hline & Group I & Group II & P value \\
\hline $\begin{array}{l}\text { Mean Actual Tissue Ablation per Eye + SD } \\
\text { [Microns] }\end{array}$ & $83.91+55.5$ & $83.85+30.41$ & 0.84 \\
\hline $\begin{array}{l}\text { Mean Actual Tissue Ablation Per One Diopter for } \\
\text { the 6.5 Treatment Zone + SD [Microns] }\end{array}$ & $13.3+0.73$ & $13.4+0.73$ & 0.71 \\
\hline $\begin{array}{l}\text { Mean Actual Tissue Ablation Per One Diopter for } \\
\text { the 6.0 Treatment Zone + SD [Microns] }\end{array}$ & $11.9+0.68$ & $11.8+0.59$ & 0.46 \\
\hline
\end{tabular}

\section{DISCUSSION}

Accurate knowledge of ablation depth is essential in LASIK and Femto-LASIK surgeries because it determines the residual stromal bed. An overestimation before surgery may result in exclusion of eligible patients from refractive surgeries, while underestimation may predispose the patient to post refractive surgeries ectasia. Munnerlyn 14 formula was used for many years to aid the surgeon in estimating the ablation depth. Nowadays, more complex ablation profiles, such as wavefront, wavefront optimized, or topography guided, complicate the calculation of ablation depth. Consequently, the refractive surgeon relies on the estimated ablation depth provided by the laser machine's software ${ }^{[11]}$.

In our study, forty eyes in 20 patients with myopia or myopic astigmatism were included. They were subjected to correct their errors of refraction by Lasik or Femto-Lasik surgeries. They were classified into 2 groups according to the technique used for the treatment. In group I: the microkeratome was used in all cases to form a lamellar hinged superior flap [110 microns] using the Moria II microkeratome. In group II: corneal flap [110 microns] was formed using the Femto-Laser machine [FS200]. After formation of the flap in both groups, laser was focused on the corneal stromal bed using the Excimer-Laser Wave Light EX500 in a $6.5 \mathrm{~mm}$ or $6.0 \mathrm{~mm}$ treatment zones, depending on the scotopic pupil size.

According to the calculations provided to us by the software of the Excimer laser machine, the mean calculated tissue ablation per eye was 90.12 microns, mean calculated tissue ablation per one diopter was 14.4 microns for the 6.5 $\mathrm{mm}$ treatment zone, and 13.1 microns for the $6.0 \mathrm{~mm}$ treatment zone. In Group II, the mean calculated tissue ablation per eye was 91.57 microns, mean calculated tissue ablation per one diopter was 14.3 microns for $6.5 \mathrm{~mm}$ treatment zone, and 13.2 microns for $6.0 \mathrm{~mm}$ treatment zone. Difference between both groups as regards the calculated tissue ablation per one diopter was statistically insignificant.

Three months postoperatively, the mean actual ablation per eye and per one diopter was obtained. In Group I, the mean actual thinnest corneal location was 465.88 microns, mean actual tissue ablation per eye was 83.91 microns, mean actual tissue ablation per one diopter was 13.3 microns for $6.5 \mathrm{~mm}$ treatment zone, and 11.9 microns for $6.0 \mathrm{~mm}$ treatment 
zone. In Group II, mean thinnest corneal location was 475.13 microns, mean actual tissue ablation per eye was 83.85 microns, mean actual tissue ablation per one diopter was 13.4 microns for 6.5 treatment zone, and 11.8 microns for 6.0 treatment zone. There were insignificant statistical differences between LASIK and Femto-LASIK groups as regards the actual tissue ablation per eye and the actual tissue ablation per diopter in both the $6.5 \mathrm{~mm}$ and $6.0 \mathrm{~mm}$ treatment zones.

A study was published in 2016 found that there is moderate agreement between predicted ablation depth [using nomogram-based adjustment] and Scheimpflug-based measured ablation depth, with an overestimation of ablation depth in lower degrees of myopia and underestimation in eyes with higher myopic correction $^{[12]}$.

Study was published in $2015^{[11]}$ where the central corneal thickness using Fourier-domain anterior segment optical coherence tomography was assessed to evaluate stromal thickness changes in eyes undergoing myopic LASIK correction. They compared the results with the laser software-planned maximum stromal ablation estimation, using a correction factor for epithelial remodeling. They found good correlation between objective stromal thickness reduction and attempted versus achieved refractive change. They reported that the laser platform estimation of ablation depth correlated well with measurements achieved by the Pentacam. Their results were analyzed considering the full refractive correction, without nomogram adjustment, as recommended by the company. They reported that it is important to consider the full refractive error, rather than the nomogramadjusted refractive error, to improve the accuracy of the actual estimated ablation depth and residual stromal bed thickness when entering the data in the laser machine software [11].

In contrast to our results, Erie et al. reported a study to correct myopia by 2 techniques, the LASIK and the PRK surgeries. They used the Visx Star S2 laser machine and the automated Hansatome microkeratome for the LASIK group, the measured ablation depth was $81 \pm 34 \mu \mathrm{m}]$, which was 25 percent greater than the predicted ablation depth $[65 \mu \mathrm{m} \pm 13$; $\mathrm{P}=.007]$.

The difference between the measured and predicted depths was statistically significant in the LASIK group, while statistically insignificant in the PRK group. Differences between the results of this study and our study may be attributed to differences in the software of the Excimer laser machines used in the two studies. It may also be attributed to difference in the sample size in the two studies.

In a study done at the Mayo Clinic found that by using confocal microscopy, the mean central ablation depth after Femtosecond Laser-Assisted LASIK is significantly greater than the predicted ablation depth. They reported that the difference between the measured and the predicted ablation depths increased when the ablation depth increased. The study also reported that there was insignificant statistical difference between the measured and the predicted ablation depths after PRK using with the same excimer laser machine ${ }^{[12]}$.

Conclusion: The actual ablation depth should be considered to calculate the remaining stromal depth after LASIK or FEMTOLASIK surgeries for treatment of myopia or myopic astigmatism to avoid the possibility of postLASIK or FEMTOLASIK ectasia and to correct the maximum error that meets the patient's needs and safety. Mean actual ablation per one diopter in $6.5 \mathrm{~mm}$ and $6.0 \mathrm{~mm}$ treatment zones were 13.4 and 13.1 microns respectively in both the LASIK and the FemtoLASIK surgeries.

Financial and non-financial relationships and activities of interest: None

\section{REFERENCES}

1. Latz C, Asshauer T, Rathjen C, Mirshahi A. Femtosecond-Laser Assisted Surgery of the Eye: Overview and Impact of the Low-Energy Concept. Micromachines [Basel]. 2021 Jan 24;12[2]:122. DOI: 10.3390/mi12020122.

2. Binder PS, Trattler WB. Evaluation of a risk factor scoring system for corneal ectasia after 
LASIK in eyes with normal topography. J Refract Surg. 2010 Apr;26[4]:241-50. DOI: 10.3928/1081597X-20100212-02.

3. Mohamadpour M, Khorrami-Nejad M, Kiarudi MY, Khosravi K. Evaluating the Ectasia Risk Score System in Cancelled Laser in Situ Keratomileusis Candidates. J Ophthalmic Vis Res. 2020 Oct 25;15[4]:481-485. DOI: 10.18502/jovr.v15i4.7788.

4. Yang K, Xu L, Fan Q, Gu Y, Song P, Zhang B, et al. Evaluation of new Corvis ST parameters in normal, Post-LASIK, Post-LASIK keratectasia and keratoconus eyes. Sci Rep. 2020 Mar 30;10[1]:5676. DOI: 10.1038/ s41598-020-62825-y.

5. Ambrósio R Jr, Dawson DG, Belin MW. Association between the percent tissue altered and post-laser in situ keratomileusis ectasia in eyes with normal preoperative topography. Am J Ophthalmol. 2014 Dec;158[6]:1358-9. DOI: 10.1016/j.ajo.2014.09.016.

6. Mohammadpour M, Mohammad K, Karimi N. Central Corneal Thickness Measurement Using Ultrasonic Pachymetry, Rotating Scheimpflug Camera, and Scanning-slit Topography Exclusively in Thin Nonkeratoconic Corneas. J Ophthalmic Vis Res. 2016;11[3]:245-51. DOI: 10.4103/2008-322X. 188392.

7. Can E, Eser-Ozturk H, Duran M, Cetinkaya T, Ariturk N. Comparison of central corneal thickness measurements using different imaging devices and ultrasound pachymetry. Indian J Ophthalmol. 2019 Apr;67[4]:496-499. DOI: 10.4103/ijo.IJO_960_18.

8. Nassiri N, Sheibani K, Safi S, Nassiri S, Ziaei A, Haji F, Mehravaran S, Nassiri N. Central Corneal Thickness in Highly Myopic Eyes: Inter-device Agreement of Ultrasonic Pachymetry, Pentacam and Orbscan II Before and After Photorefractive Keratectomy. J Ophthalmic Vis Res. 2014 Jan;9[1]:14-21. Erratum in: J Ophthalmic Vis Res. 2015 AprJun;10[2]:208. PMID: 24982727
9. Ho WC, Lam PT, Chiu TY, Yim MC, Lau FT. Comparison of central corneal thickness measurement by scanning slit topography, infrared, and ultrasound pachymetry in normal and post-LASIK eyes. Int Ophthalmol. 2020 Nov;40[11]:2913-2921. DOI: 10.1007/s10792020-01475-5.

10. Binnawi KH, Elzubeir H, Osman E, Abdu M, Abdu M. Central corneal thickness measurement using ultrasonic pachymeter, optical coherence tomography, and TMS-5 topographer. Oman J Ophthalmol. 2019 JanApr;12[1]:15-19. DOI: 10.4103/ojo.OJO_96_ 2018.

11. Kanellopoulos AJ, Georgiadou S, Asimellis G. Objective Evaluation of Planned Versus Achieved Stromal Thickness Reduction in Myopic Femtosecond Laser-assisted LASIK. J Refract Surg. 2015 Sep;31[9]:628-32. DOI: 10.3928/1081597X-20150820-09.

12. Savini G, Cummings AB, Balducci N, Barboni P, Huang J, Lombardo M, Serrao S, Ducoli P. Agreement Between Predicted and Measured Ablation Depth After Femtosecond LaserAssisted LASIK for Myopia. J Refract Surg. 2016 Mar;32[3]:164-70. DOI: 10.3928/ 1081597X-20160121-03.

13. Erie JC, Hodge DO, Bourne WM. Confocal microscopy evaluation of stromal ablation depth after myopic laser in situ keratomileusis and photorefractive keratectomy. J Cataract Refract Surg. 2004 Feb;30(2):321-5. DOI: 10.1016/j.jcrs.2003.09.058. 


\section{i1: $12(22$}

international Journal

https://ijma.journals.ekb.eg/

Print ISSN: 2636-4174

Online ISSN: 2682-3780

of Medical Arts 